\title{
Clinical Trial Subject
}

National Cancer Institute

\section{Source}

National Cancer Institute. Clinical Trial Subject. NCI Thesaurus. Code C70668.

A living person who is observed, analyzed, examined, investigated, experimented upon, and/or treated in the course of a clinical trial. This includes studies where an investigator obtains identifiable private information or data through the intervention or interaction with the individual. 